\title{
Psychiatric education in Yorkshire
}

\section{The Yorkshire Regional Psychiatric Association: 40 years - 1949-1989}

\author{
D. A. SPEnCER, Consultant Psychiatrist, Meanwood Park Hospital, Leeds
}

The Yorkshire Regional Psychiatric Association is a group of psychiatrists, general practitioners, psychologists, nurses, social workers, occupational therapists, chaplains, health managers and others working in the field of mental health. Its main functions are to promote vocational, academic and social discourse between members of the professions with an interest in mental health and handicap. It has about $\mathbf{3 0 0}$ members. The Association was founded in January 1949 as the Leeds Regional Psychiatric Association. This became the Yorkshire Regional Psychiatric Association in 1982. In 1989 the Association reaches its 40th anniversary. The Association can claim the distinction of being the first multiprofessional society of workers in mental health to be established in the United Kingdom.

\section{Founding of the Association}

Dr James Valentine, a founder member, who was the Medical Superintendent at Scalebor Park Hospital, Burley in Wharfedale, West Yorkshire, has recalled that the germ of the idea of an Association was planted on Sunday, 23 May 1948 when Professor Henry Dicks, Nuffield Professor of Psychiatry at Leeds, and Dr Valentine were walking along the River Wharfe by Bolton Abbey. Professor Dicks was trying to instill an interest in psychiatry in its broader aspects by holding weekly open discussions in Leeds Infirmary and the department in Blundell Street, Leeds, at which colleagues from all departments of the University and Medical School were made welcome.

There already existed regular meetings of the Medical Superintendents of the Yorkshire Mental Hospitals which Professor Dicks attended. Dr Valentine had told Professor Dicks about a Scottish psychiatric club, a society formed in the thirties by junior doctors for the presentation of papers and journal reviews. Professor Dicks and Dr Valentine thought that it would be worthwhile to form a similar society in Yorkshire, but open to psychiatrists at all levels and others working in the field. During the summer and autumn of 1948 the idea was discussed with Dr J. W. Affleck, who was in charge of psychi- atric services in Leeds, Dr John Lowe, the first Leeds Regional Psychiatrist, and colleagues in the Leeds Region. A small steering committee was set up. A general meeting to form the Leeds Regional Psychiatric Association was called on Saturday, 29 January 1949. Two or three successive meetings of the Association and its committee were held in the boardroom of the Leeds Infirmary on 18 November 1949 and the first meeting to have an outside speaker was addressed by Professor T. Ferguson Rodger from Glasgow University.

\section{Founder members}

Professor Dicks was elected first Chairman of the Association and Dr James W. Affleck was the first Secretary, a position he held to 1957. Then he was succeeded by Dr Eric Jeffrey Harrison of Scalebor Park, who went to Tasmania and later Western Australia. He died prematurely and tragically of motor neurone disease in Perth. The second Chairman was Dr W. F. Roper of Wakefield prison, the third, Dr J. Valentine, from 1951. A stimulus to the formation of the Association was the infrequency of convenient Royal Medico-Psychological Association meetings which were then based on an area which stretched from Sheffield to Newcastle.

\section{Objects of the Association}

The idealism and enthusiasm of the Association's founders were reflected in the early constitutions of the Association. These stated that the main object of the Association shall be to promote and improve the mental health of the individual and community by:

(1) study of the clinical, social, educational and administrative problems of psychiatric practice, and

(2) representation of the views of the Association to the proper authorities, the medical and other professions and the public.

In later years clause (2) was dropped as other agencies began to fulfil its objectives. Since 1972 the 
Association's constitution has stated that the objects of the Association shall be to promote and improve the mental health of the individual and the community, involving study of the clinical, social, educational and administrative problems of psychiatric practice.

\section{Membership}

When founded, in addition to registered medical practitioners engaged in, or training for, specialist practice in psychiatry, the Association offered Associate Membership to psychologists, psychiatric social workers, lay therapists, registered nurses in mental illness and mental handicap, family doctors, and others whose particular contributions entitled them to special consideration.

By 1972 the Association had changed its constitution and created only one class of membership with voting powers. Membership was open to all registered medical practitioners and members of other disciplines engaged predominantly in mental health work.

The Association offers honorary membership to individuals who have made outstanding contributions to psychiatry or to the Association and are elected as honorary members by a two thirds majority of members at a general meeting.

\section{Executive committee}

In its earlier years the Association had a large and complicated Executive Committee structure to ensure as wide a representation of interest as possible. The Association has always had a Chairman, ViceChairman, Honorary Secretaries and Honorary Treasurer. In 1959 the Executive Committee comprised a representative of the Leeds University Department of Psychiatry, six representatives of the Regional Hospital Board Psychiatrists, two representatives of non-regional Board Psychiatrists, a representative lay therapist, general practitioner, mental nurse, psychologist, psychiatric social worker, and others. In recent years the Executive Committee has consisted of the five officers and ten sthers.

\section{Annual programme}

The Association's annual programme has consisted typically of 10 to 12 evening meetings held at two to four weekly intervals between late September and late May in the following year. One meeting has been a social event, another devoted to the Annual General Meeting. The meetings, usually lectures, have been planned by the Executive Committee which has aimed to cover a variety of subjects in the field of mental health. In the late seventies and early eighties the Association held a number of half-day symposia. Since 1980 the Association has used the facilities of the Clinical Sciences Building at St James's University Hospital, Leeds.

\section{Study groups}

For many years, in addition to its ordinary meetings, the Association organised a number of study groups which met regularly under their own separate conveners. There were study groups for psychosomatic studies, psychotherapy, long associated with $\mathrm{Dr}$ W. E. Sargant of Leeds until his death in the midseventies, delinquency and mental nursing. In more recent years a rehabilitation study group was formed which met up in 1984.

\section{Hargreaves Memorial Lectures}

After the untimely death in 1962 of Professor George Ronald Hargreaves, OBE, MSc, FRCPE, Nuffield Professor of Psychiatry at the University of Leeds from 1955, the Association inaugurated the Hargreaves Memorial Lectures. This annual lecture is held in the autumn of each year. The Association has invited distinguished speakers from inside and outside the field of psychiatry to deliver these lectures.

\section{Patron}

The Association's constitution has made reference to the appointment of a patron as follows, "the Patron shall be selected on recommendation from the Yorkshire Regional Psychiatric Association Executive Committee at the Annual General Meeting".

Professor Max Hamilton, who succeeded Professor Hargreaves as Nuffield Professor of Psychiatry at Leeds in 1964, was the Association's first Patron. At its Annual General Meeting in May 1977 the Association acknowledged emeritus Professor Hamilton's long interest in the Association by inviting patronage. He was a frequent participant in the meetings up to his death on 6 August 1988.

\section{Title, logo and subscriptions}

To maintain consistency with the Regional organisation of the restructured National Health Service in 1982, the Association changed its title. The Leeds became the Yorkshire Regional Psychiatric Association.

In 1984 the Association adopted a form of rose logo, designed with the help of Dr T. L. Pilkington, a consultant member of the committee. 
The Association has always endeavoured to keep its subscriptions to a minimum. In the fifties membership cost ten shillings a year. In the sixties this had risen to 21 shillings. In 1974 the subscription was $£ 2$ for consultants and $£ 1$ for others. In the eighties the subscription is $£ 5$ for consultants, $£ 3$ for others. Membership is, therefore, extremely good value. In 1977 the Association was recognised as a learned body for taxation purposes.

\section{Acknowledgements}

During the $\mathbf{4 0}$ years of its existence the Yorkshire Regional Psychiatric Association has held nearly 500 lectures. Most psychiatrists of distinction and many other professionals and personalities well-known and respected in their particular callings have lectured at some time to the Association. Like many academic bodies, the Association has never had the resources to offer speakers more than token fees beyond meeting their expenses. The Association has survived so far on the modest principle that an individual's being invited to give a lecture is an honour in itself, an opportunity to contribute to psychiatric education and to win recognition and regard among colleagues. Lecturers to the Association have fre- quently been able to develop their scripts for publication later elsewhere.

In the past the Association's lectures and study groups have helped to fill gaps in professional education. With the establishment of the Royal College of Psychiatrists, the introduction of approved schemes of training and the growth of academic departments, the role of the YRPA in professional education has diminished. It now complements professional training programmes and provides a forum where professionals can meet colleagues from their own and related disciplines. There they can discuss and share problems and reach less isolated, more relaxed and detached feelings about professional practice. The social element of the meetings can help to relieve and to put into perspective many of the tensions and pressures which professionals face in their day to day commitments.

The Association will be ever grateful to all who have helped to sustain its programmes, to lecturers, to sponsors for financial support, to the many people who have voluntarily and freely given their time as elected officers and committee members, to the Health Authorities which have granted it some concessions, and to a loyal membership which has attended the meetings.

\section{Monitoring community care in York}

\section{Giles Harborne, Registrar in Psychiatry; and Annette Henderson, Research Nurse, Bootham Park Hospital, York}

Up to 37,000 chronic mentally ill and mentally handicapped patients have been discharged from long-stay hospitals over the past ten years and nobody knows for certain where most of them are. This is one of the findings of the 1986 Audit Commission into community care which prompted Sir Roy Griffiths (1988) to state in his report on community care that:

"a system involving the assignment of a person in need of support to an individual career, so as to become his responsibility, is rarely made, even when highly applicable e.g. in the case of patients discharged from longstay hospitals."

He goes on to recommend that in the future, especially with the closure of large mental hospitals.

"No person should be discharged without a clear package of care devised and without being the responsibility of a named care worker. This is not simply an administrative or financial process: it is intended to be a thorough process of review to guarantee that there are carefully prepared plans to ensure an optimal quality of life for the individuals leaving hospital."

The subject of patient monitoring has already been promoted at top NHS management level in terms of assessing service quality and maintaining responsibility after the closure of long-stay hospitals. It is apparent that to implement these recommendations simple but effective methods of patient monitoring and management will be needed in every district as soon as possible.

The most substantial system reported so far, although still in the developmental stage, is the Friern Hospital schizophrenia follow-up study (Pantelis, et al, 1988). This is an expensive and specialised project which promises to provide a detailed and continuously updated assessment on all people with schizophrenia within the catchment area. 